\title{
Compression and consolidation anisotropy of some soft soils
}

\author{
BRENDAN C. O'KELLY ${ }^{\star}$ \\ Department of Civil, Structural and Environmental Engineering, University of Dublin, Trinity \\ College, Dublin, 2, Ireland (phone + 3531608 2387; fax + 3531677 30725; \\ e-mail: bokelly@tcd.ie)
}

(Received 10 February 2005; accepted 7 December 2005)

\begin{abstract}
The compression and consolidation anisotropy of 11 soft soils were studied by conducting oedometer tests on sets of duplicate undisturbed specimens prepared in the vertical and horizontal directions from adjacent sections of carefully sampled borehole cores. The onedimensional compression, yield and creep characteristics of the various silts, clays and amorphous peaty material tested were similar for the vertical and horizontal directions. The exception was the structured, coarse fibrous peaty material which was strongly cross-anisotropic. Drainage occurred more rapidly in the horizontal direction with horizontal-to-vertical permeability ratios $r_{k}$ of 1.0-1.7. Higher $r_{k}$ values were associated with more marked fabrics, namely for clays with fine sand partings, fibrous organic inclusions or fine root-holes and the laminated silts. The $r_{k}$ value was for practical purposes independent of the stress level.
\end{abstract}

Key words. anisotropy, consolidation, fabric, one-dimensional compression, permeability, soft soil.

\section{Introduction}

Soft soil deposits are often cross-anisotropic in their mechanical and drainage properties due to the preferred horizontal alignment of the solid particles during deposition and subsequent consolidation under the overburden weight. Hence, the rate of consolidation is often greater for horizontal than for vertical drainage conditions and the state of anisotropy can be assessed in terms of the horizontal-to-vertical permeability ratio $r_{k}$. Table 1 lists typical $r_{k}$ values reported for soft natural clayey deposits.

Accurate predictions of the amount and in particular the rate of settlement of the ground under an applied load are necessary since geotechnical design is largely driven by serviceability limit state conditions. The consolidation properties of the ground are often determined in practice using standard oedometer tests for vertical drainage conditions only. The measurement of the consolidation properties under horizontal drainage conditions receives less attention and an assessment of the state of anisotropy in terms of the permeability ratio is often made on the basis of the soil description and engineering judgment. Consequently, design predictions for the field

^ Formerly Scott Wilson Consulting Engineers, UK. 
Table 1. Horizontal-to-vertical permeability ratios $r_{k}$

\begin{tabular}{lll}
\hline Description & $r_{k}$ & Reference \\
\hline Soft marine clay & 1.05 & Subbaraju (1973) \\
Plastic marine clay & 1.2 & Lumb and Holt (1968) \\
Bäckebol soft marine clay & $1.18-1.33$ & Leroueil et al. (1990) \\
Louiseville soft marine clay & 1.35 & Leroueil et al. (1990) \\
Organic silt with peaty & $1.2-1.7$ & Tsien (1955) \\
Soft clay & 1.5 & Basett and Brodie (1961) \\
Bothkennar soft silty clay & $1.5-2.0$ & Leroueil et al. (1992) \\
Po soft clay & $1.4-2.5$ & Cortellazzo and Simonini (2001) \\
Soft Bangkok clay & $1.3-2.8$ & Seah and Koslanant (2003) \\
Singapore marine clay & $2.0-3.0$ & Chu et al. (2002) \\
Po soft silty clay & $2.7-4.0$ & Cortellazzo and Simonini (2001) \\
\hline
\end{tabular}

consolidation rate are generally conservative (Cortellazzo and Simonini, 2001). It was in this context that the degree of compression, consolidation and permeability anisotropy of various soft soils were studied by comparing the responses of duplicate sets of specimens under one-dimensional loading for vertical and horizontal drainage conditions.

\section{Test Programme}

Standard oedometer tests were conducted on duplicate sets of undisturbed specimens, $76.2 \mathrm{~mm}$ in diameter by $19.0 \mathrm{~mm}$ in height, that were prepared from adjacent sections of carefully sampled borehole cores, one set carved out and tested in the vertical direction and the other set carved out and tested in the horizontal direction. The cores were recovered in $100 \mathrm{~mm}$ diameter aluminium tubes (12 degree cutting edge and an area ratio of $7 \%$ ) using a fixed-piston sampler. The oedometer tests comprised five maintained-load stages, each stage of $24 \mathrm{~h}$ duration. The applied axial stress range was $12.5-200 \mathrm{kPa}$ and a stress increment ratio of unity was used throughout. Specimen drainage was facilitated via porous top and bottom loading platens and the axial deformation was recorded using a displacement transducer.

Table 2 lists the description, index and in situ properties of the test soils that were obtained from four sites in Ireland (Figure 1). The Carrick on Shannon site was an alluvial deposit; the Carrickmacross site a lacustrine deposit; the Shannon site an alluvial and marshland deposit; and the Waterford site an estuarine deposit. The various soils were identified by labels [1] to [11]. The small-scale fabrics of the undisturbed cores were noted following a careful visual inspection. The two peaty materials [10] and [11] were classified as $\mathrm{H} 3$ (spongy fibrous plant material that was only slightly biodegraded) and H6 (amorphous material that was strongly biodegraded) according to the von Post system (Head, 1992). 


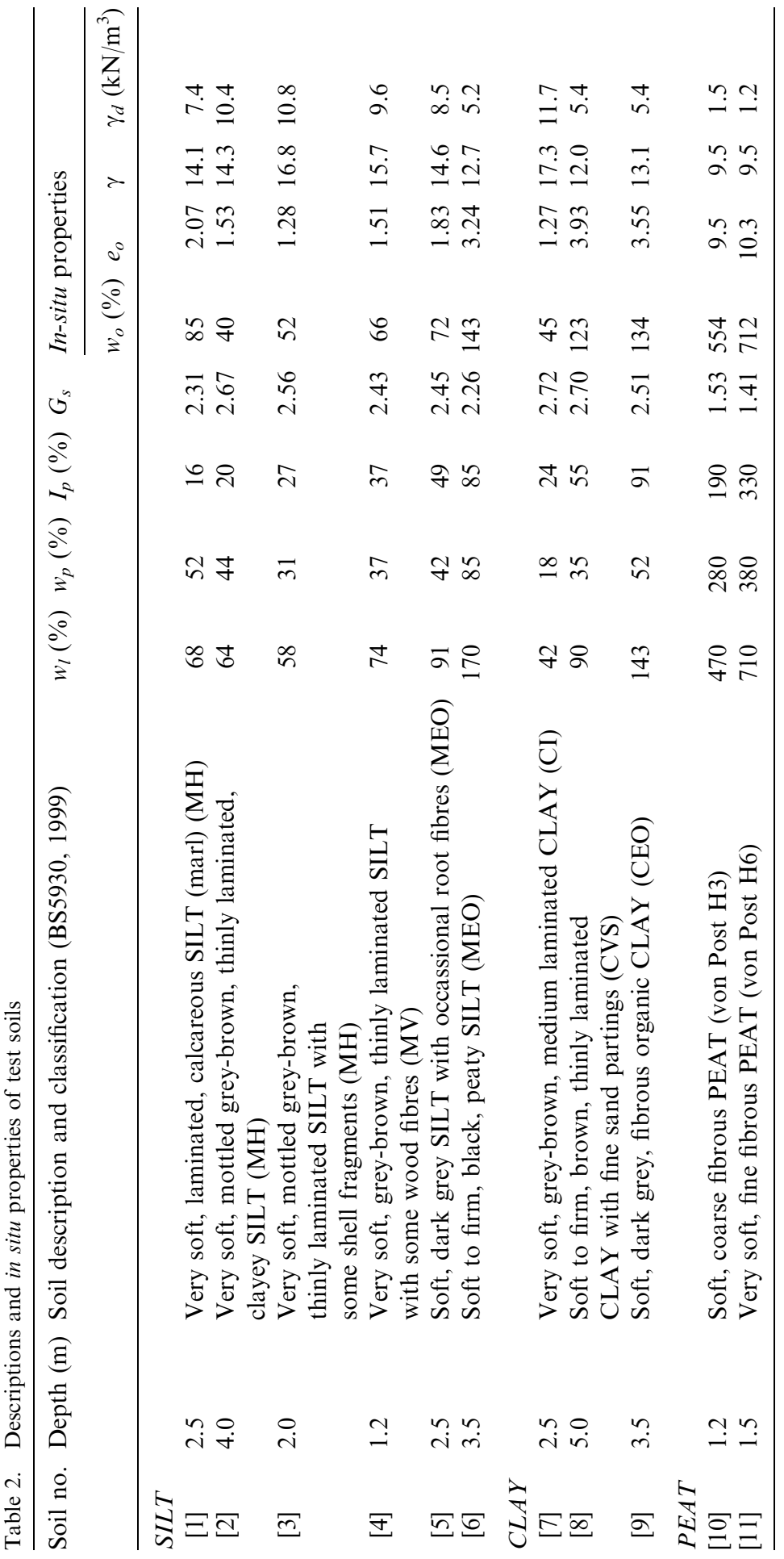




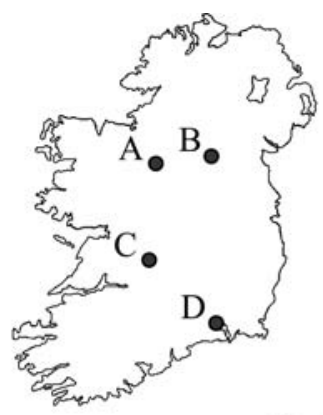

Test soil number
A : Carrick on Shannon
$[5,8,9,10,11]$
B : Carrickmacross
$[1,7]$
C : Shannon
[6]
D : St. John's Estuary, Waterford
$[2,3,4]$

Figure 1. Locations of soft soil deposits in Ireland.

\section{Experimental Results}

Similar initial water content, void ratio and bulk unit weight values measured for the specimen sets confirmed that they were duplicate sets. Figure 2 shows the oedometer data for the various soils. The initial specimen compression recorded for the different oedometer load stages was negligible indicating that the specimens were fully saturated. Figure 3 shows the compressibility of the soils in terms of void ratio-logarithm effective stress $\left(e-\log \sigma^{\prime}\right)$ plots. Table 3 lists the compression properties for the vertical direction in terms of the primary compression index $C_{c}$, and the primary compression ratio $C_{c}{ }^{*}$, (Equation 1).

$$
C_{c}^{*}=\frac{C_{c}}{1+e_{o}}
$$

where $e_{o}=$ the in situ void ratio and $C_{c}=$ the primary compression index.

The yield stress, in situ vertical effective stress $\left(\sigma_{v o}^{\prime}\right)$ and apparent overconsolidation ratio (OCR) are also listed in Table 3. The yield stresses for the vertical $\left(\sigma_{v c}^{\prime}\right)$ and horizontal $\left(\sigma_{h c}^{\prime}\right)$ directions were determined using the construction of compression curves after Casagrande (1936). The in situ vertical effective stress due to the overburden was calculated using the bulk unit weights and ground water level reported in the borehole log. $\sigma_{v o}^{\prime}$ was zero for the peaty materials $[10,11]$ since their buoyant weight were zero. The apparent OCR was calculated as the $\sigma_{v c}^{\prime}$ to $\sigma_{v o}^{\prime}$ ratio, a value of unity indicative of recent, normally consolidated deposits.

\section{Experimental Analysis}

\subsection{COMPRESSION AND YIELD BEHAVIOUR}

Although the soils were marginally more compressible in the vertical direction than in the horizontal direction under one-dimensional loading, for practical purposes the 

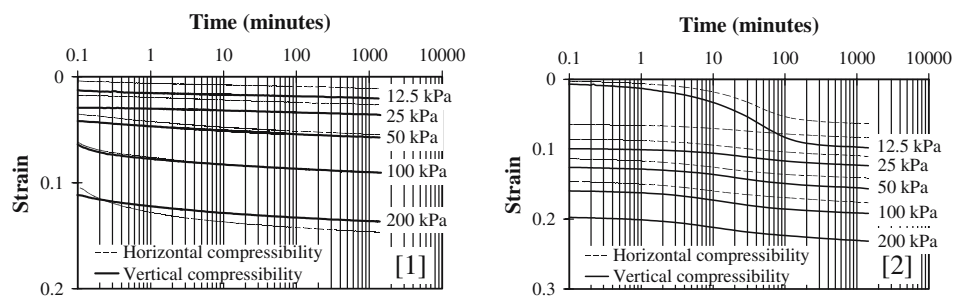

Time (minutes)

Time (minutes)
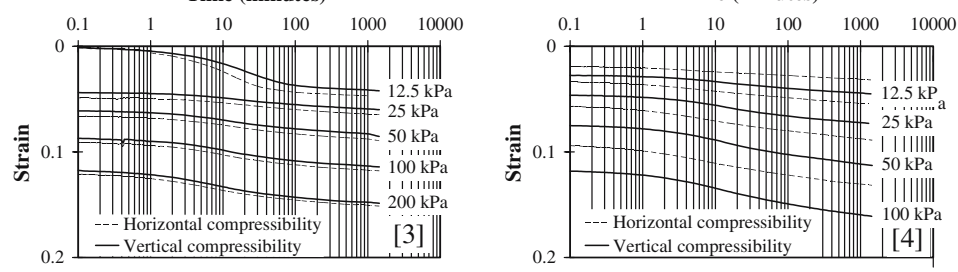

Time (minutes)
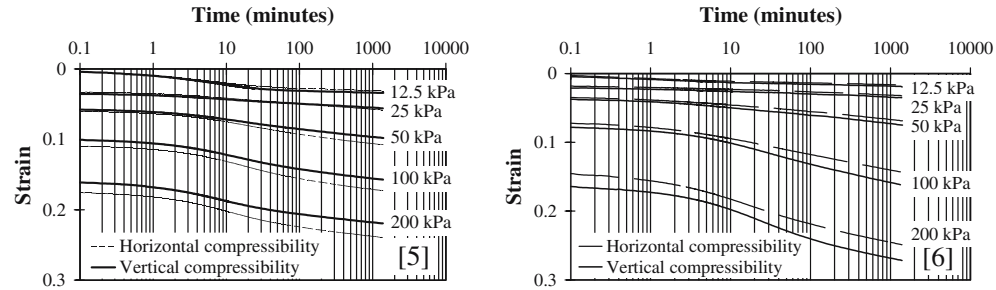

Time (minutes)
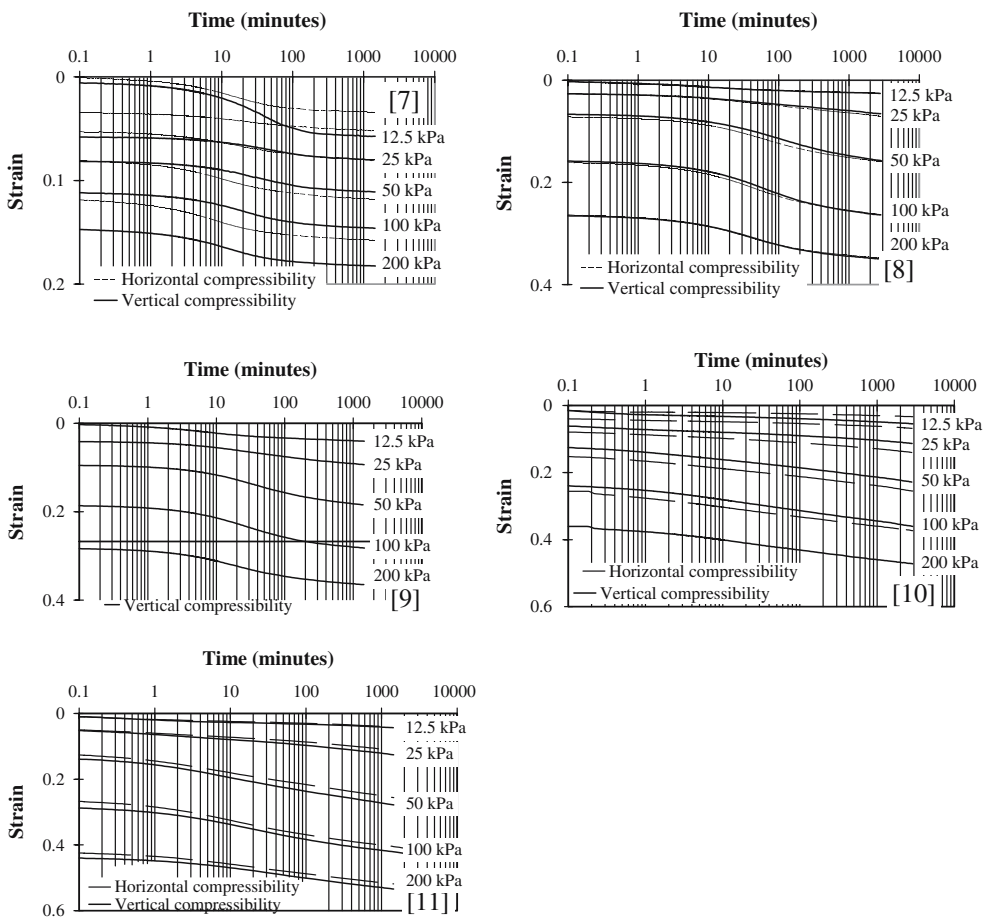

Figure 2. Cumulative strain $-\log$ time plots for test soils [1-11]. 

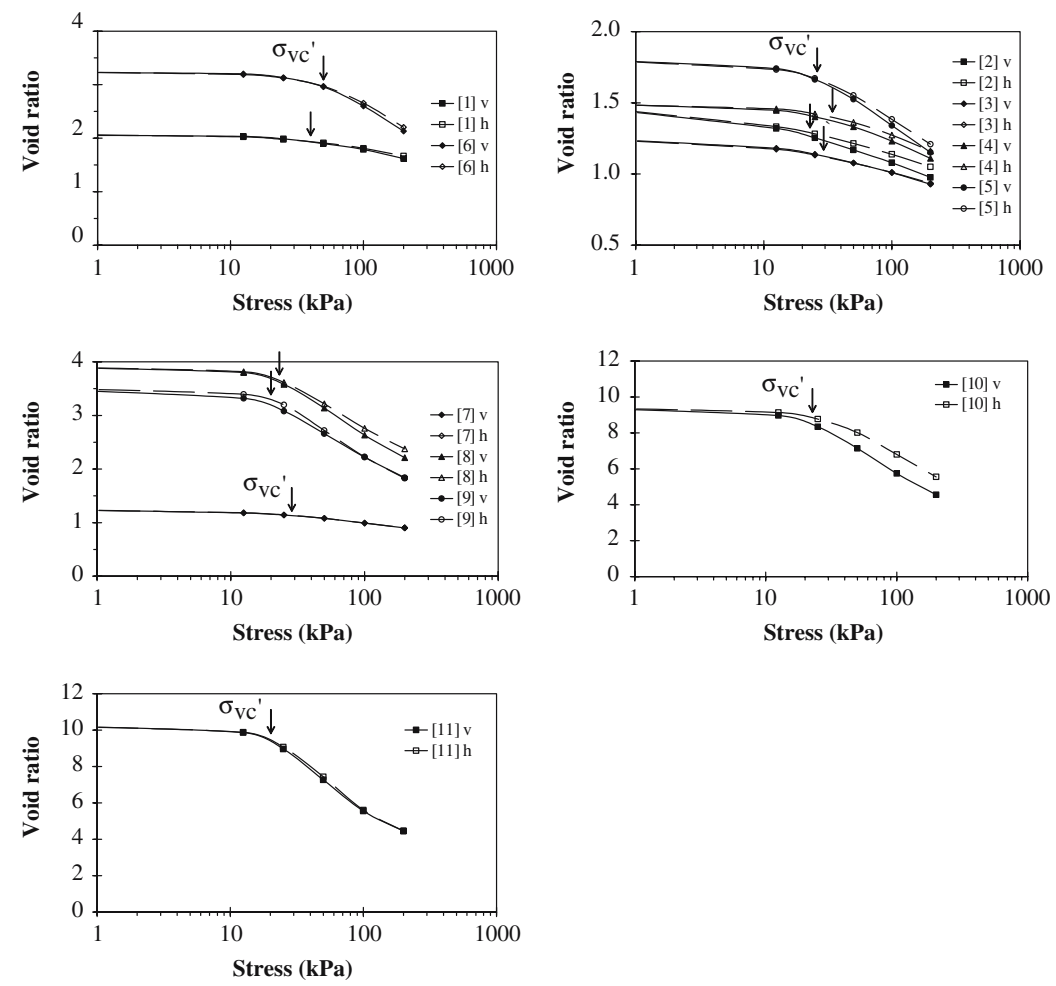

Figure 3. Compression properties for the vertical $v$, and horizontal $h$, directions.

Table 3. Compression properties for the vertical $v$, and horizontal $h$, directions

\begin{tabular}{|c|c|c|c|c|c|c|c|}
\hline \multirow[b]{2}{*}{$\begin{array}{l}\text { Test } \\
\text { soil no. }\end{array}$} & \multicolumn{2}{|c|}{$\begin{array}{l}\text { Compression } \\
\text { index }\end{array}$} & \multirow[t]{2}{*}{$\begin{array}{l}\text { Compression } \\
\text { ratio } C_{c}^{*}\end{array}$} & \multicolumn{2}{|c|}{$\begin{array}{l}\text { Preconsolidation } \\
\text { pressures }(\mathrm{kPa})\end{array}$} & \multirow[t]{2}{*}{$\begin{array}{l}\sigma_{v o}^{\prime} \\
(\mathrm{kPa})\end{array}$} & \multirow[t]{2}{*}{$\mathrm{OCR}_{v}$} \\
\hline & $C_{c}$ & $h: v$ ratio & & $\sigma_{v c}^{\prime}$ & $\sigma_{h c}^{\prime}$ & & \\
\hline [1] & 0.59 & 0.8 & 0.19 & 40 & 40 & 12 & 3.4 \\
\hline [2] & 0.35 & 0.9 & 0.14 & 21 & 25 & 20 & 1.0 \\
\hline [3] & 0.28 & 0.9 & 0.12 & 29 & 29 & 16 & 1.9 \\
\hline [4] & 0.42 & 0.9 & 0.17 & 33 & 36 & 9 & 3.8 \\
\hline [5] & 0.64 & 0.9 & 0.22 & 25 & 27 & 13 & 1.9 \\
\hline [6] & 1.6 & 1.0 & 0.37 & 50 & 51 & 10 & 5.0 \\
\hline [7] & 0.30 & 1.0 & 0.13 & 29 & 28 & 20 & 1.4 \\
\hline [8] & 1.7 & 0.9 & 0.34 & 21 & 22 & 12 & 1.8 \\
\hline [9] & 1.5 & 1.1 & 0.33 & 20 & 21 & 12 & 1.7 \\
\hline [10] & 4.7 & 0.9 & 0.45 & 21 & 32 & 0 & - \\
\hline [11] & 6.0 & 1.0 & 0.53 & 20 & 22 & 0 & - \\
\hline
\end{tabular}


responses were similar when assessed in terms of cumulative strains (Figure 2), reductions in void ratio (Figure 3) or the ratios of the horizontal-to-vertical primary compression indices (Table 3). The exception was the coarse fibrous peaty material [10], which was strongly cross-anisotropic, particularly at stresses below the yield stress. In general, the yield stresses for the vertical and horizontal directions were equal since the specimen sets had experienced the same mean in situ effective confining stress.

The OCR values were generally slightly greater than unity due to geological ageing. Figure 4 shows the primary compression ratio $C_{c}^{*}$ plotted against logarithm in situ water content. The data points generally located within $15 \%$ of the empirical correlation line (after Lambe and Whitman, 1979). The cores of the peaty materials [10, 11] were found to have been preloaded during piston sampling due to the cutting resistance of the fibrous plant material even though the sampling tube had a sharp 12 degree cutting edge.

\subsection{PRIMARY CONSOLIDATION AND PERMEABILITY}

Table 4 lists the coefficient of consolidation values for the vertical direction $c_{v v}$, and the ratios of the horizontal-to-vertical coefficients of consolidation. The coefficient of consolidation values were calculated from interpretation of the strain-time plots using Terzaghi's one-dimensional consolidation theory. The Logarithm-of-Time curve fitting method (Casagrande and Fadum, 1940) was found to be more reliable in interpreting the data and was used instead of the Square-Root-Time curve fitting method (Taylor, 1942). Su's Maximum-Slope curve fitting method (Das, 1997) in which the data was also analysed in terms of a logarithm timescale was used for the more organic soils $[6,10,11]$. The experimental curves for these soils did not exhibit the characteristic S-shape form of the theoretical curves given by Terzaghi's consolidation, theory hence their consolidation properties could not be determined from the available data. An inspection of the compression curves corresponding to the first load stage in Figure 2 also suggested that the laminated silts [2, 3] and laminated clay [7] suffered some sampling disturbance, most likely due to the cores swelling on

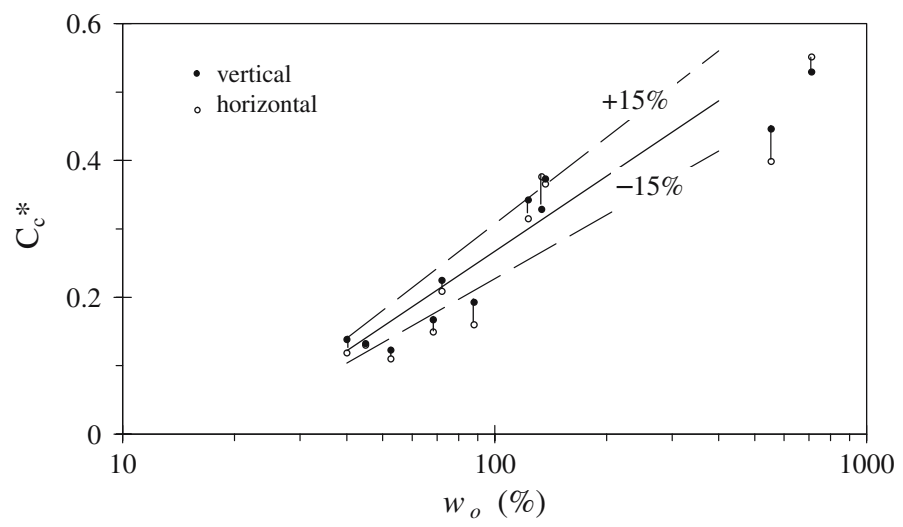

Figure 4. Primary compression ratio - log in situ water content. 


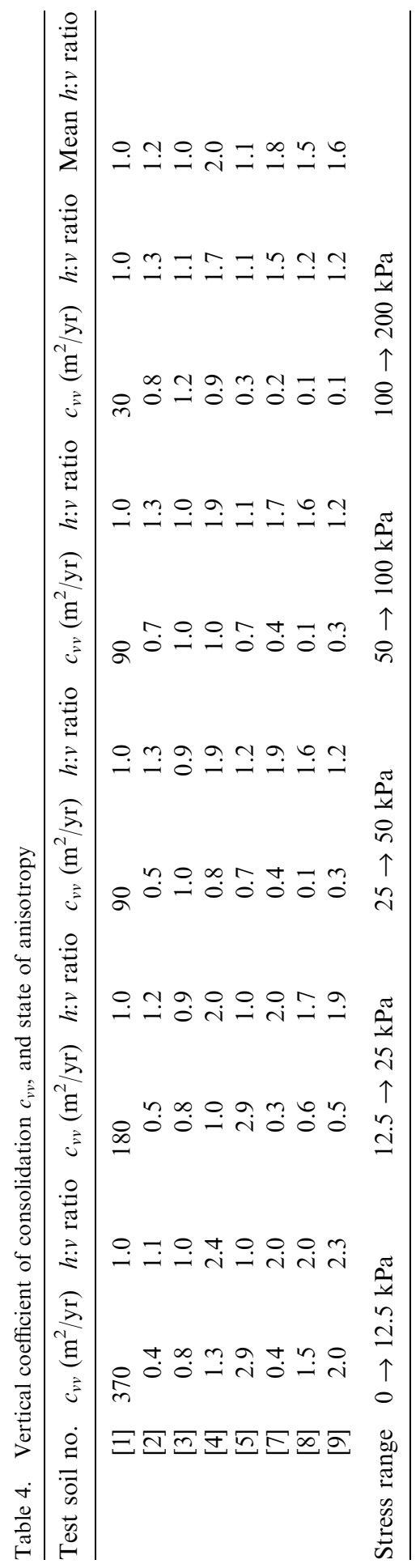


recovery from the ground. Hence, the corresponding values of the consolidation parameters were treated with caution.

Table 5 lists the coefficient of permeability values for vertical drainage conditions $k_{v}$, and the horizontal-to-vertical permeability ratio $r_{k}$. The permeability values were calculated indirectly using Equation (2) and corresponded to an ambient laboratory temperature of $21^{\circ} \mathrm{C}$.

$$
k_{v}=m_{v v} c_{v v} \gamma_{w}
$$

where $m_{v v}=$ the coefficient of volume change for the vertical direction; $c_{v v}=$ the coefficient of consolidation for the vertical direction and $\gamma_{w}=$ the unit weight of water.

The data in Tables 4 and 5 indicate that drainage occurred more rapidly in the horizontal direction than in the vertical direction. The exceptions were the calcareous silt [1] and shelly silt [3] which had similar permeability values for the vertical and horizontal directions. The range of mean $r_{k}$ values of 1.0-1.7 for the various soils was consistent with the values reported in the literature (Table 1). Higher $r_{k}$ values of 1.4-1.7 were associated with more marked fabrics, in particular those including fine sand partings, fibrous organic inclusions or fine root-holes, namely the laminated silt [4], laminated clays [7, 8] and fibrous organic clay [9]. The $r_{k}$ ratio was for practical purposes independent of the applied stress. Figure 5 shows $\log k_{v}$ plotted against $\log$ $\sigma_{v}^{\prime}$ (after Lambe and Whitman, 1979) which suggests an inverse log-log relationship. The lines included in Figure 5 are least-square best-fit regression lines. The significant reductions in the permeability at higher effective stresses for soils $[5,8,9]$ can be explained by the closure of the fine root holes and sand-filled fissures that had facilitated preferential drainage at lower effective stresses.

The data in Tables 1 and 5 can be applied in practice to obtain more accurate predictions for the rate of consolidation settlement in the field. The permeability properties measured using the oedometer apparatus for drainage in the vertical direction can be scaled by an appropriate $r_{k}$ value to determine the corresponding properties for drainage in the horizontal direction. The appropriate $r_{k}$ value can be estimated from Tables 1 and 5 taking into consideration the soil description, Atterberg limits and more importantly the soil fabric, noted from a careful inspection of the borehole core.

\subsection{SECONDARY COMPRESSION}

Table 6 lists the values of the secondary compression index $C_{\alpha e}$, for the vertical direction and the horizontal-to-vertical $C_{\alpha e}$ ratios. The $C_{\alpha e}$ values were calculated as the change in the void ratio that occurred over one log cycle of time during the secondary compression phase. Definitive conclusions regarding the creep properties would have required load stages in excess of $48 \mathrm{~h}$ duration whereas the oedometer load stages in this study were each of $24 \mathrm{~h}$ duration. Nevertheless, the $C_{\alpha e}$ values recorded for the vertical and horizontal directions were similar for the same applied effective stress. The exception was the coarse fibrous peaty material [10] that had an initial horizontal-to-vertical $C_{\alpha e}$ ratio of 0.6 , although this material became more 


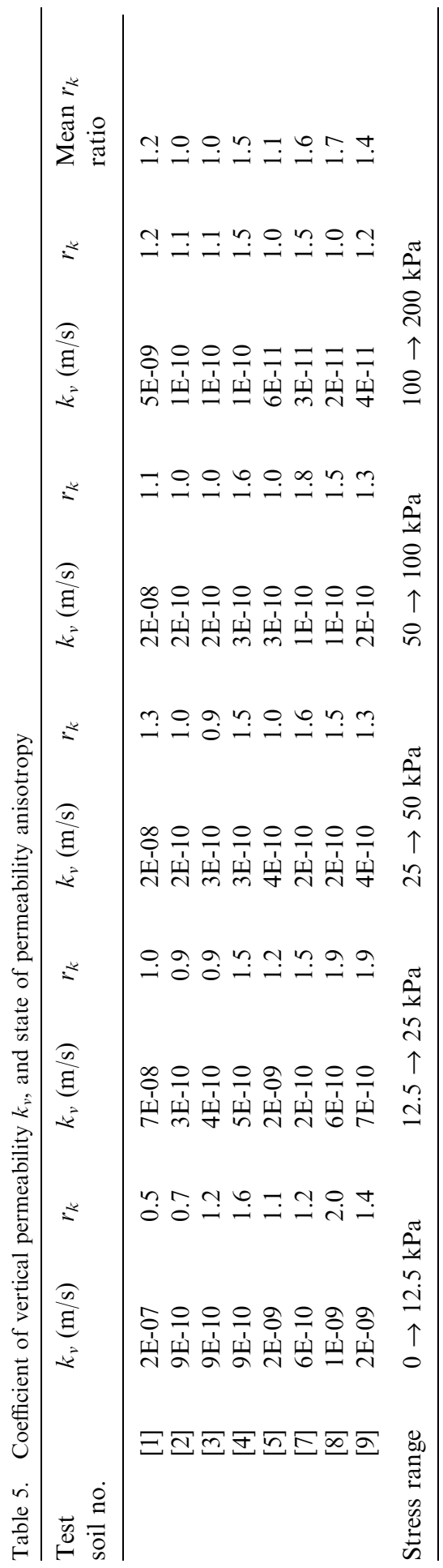



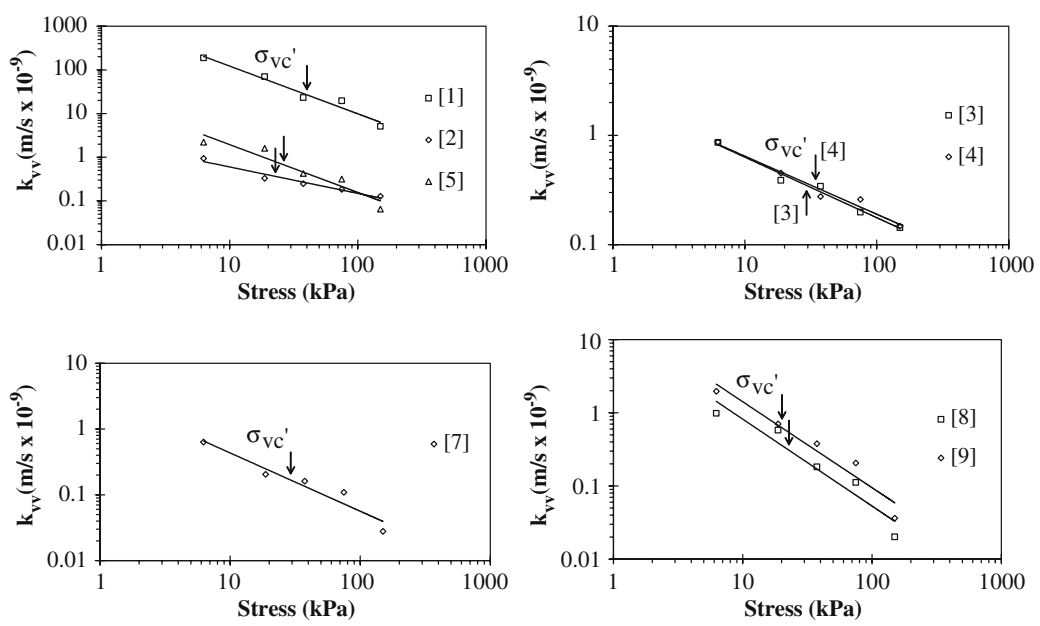

Figure 5. Coefficient of vertical permeability - log vertical effective stress.

isotropic at higher effective stresses due to the development of a new stress-induced fabric. The compressibility of the more amorphous peaty material [11] with its finer, more strongly degraded fibres was largely isotropic.

Figure 6 shows $C_{\alpha e}$ plotted against logarithm $\sigma_{v}^{\prime}$ for the test soils. A step increase in the $C_{\alpha e}$ values occurred at the yield stresses Table 6 also lists the mean values of the $C_{\alpha e} / C_{c}$ ratio calculated for applied stresses greater than the yield stress. The $C_{\alpha e} /$ $C_{c}$ values agreed with the extensive work carried out by Mesri and co-workers, for example Mesri et al. (1995), with $C_{\alpha e} / C_{c}=0.02$ for the calcareous silt [1], 0.03-0.05 for the inorganic clays and silts, and $0.05-0.06$ for the more organic soils $[6,10,11]$.

\section{Summary and Conclusions}

The one-dimensional compression and consolidation properties of 11 soft soils from Ireland were studied by conducting oedometer tests on sets of duplicate undisturbed specimens prepared in the vertical and horizontal directions from adjacent sections of carefully sampled borehole cores.

- The compression, creep and yield properties of the various silts, clays and amorphous peaty material tested were similar since the specimens sets had experienced the same mean in situ effective confining stress. The exception was the structured, coarse fibrous peaty material which was strongly cross-anisotropic.

- Drainage occurred more rapidly in the horizontal direction with horizontalto-vertical permeability ratios $r_{k}$, of $1.0-1.7$. Higher $r_{k}$ values of $1.4-1.7$ were associated with more marked fabrics, in particular clays with fine sand partings, fibrous organic inclusions or fine root holes and the laminated silts. 


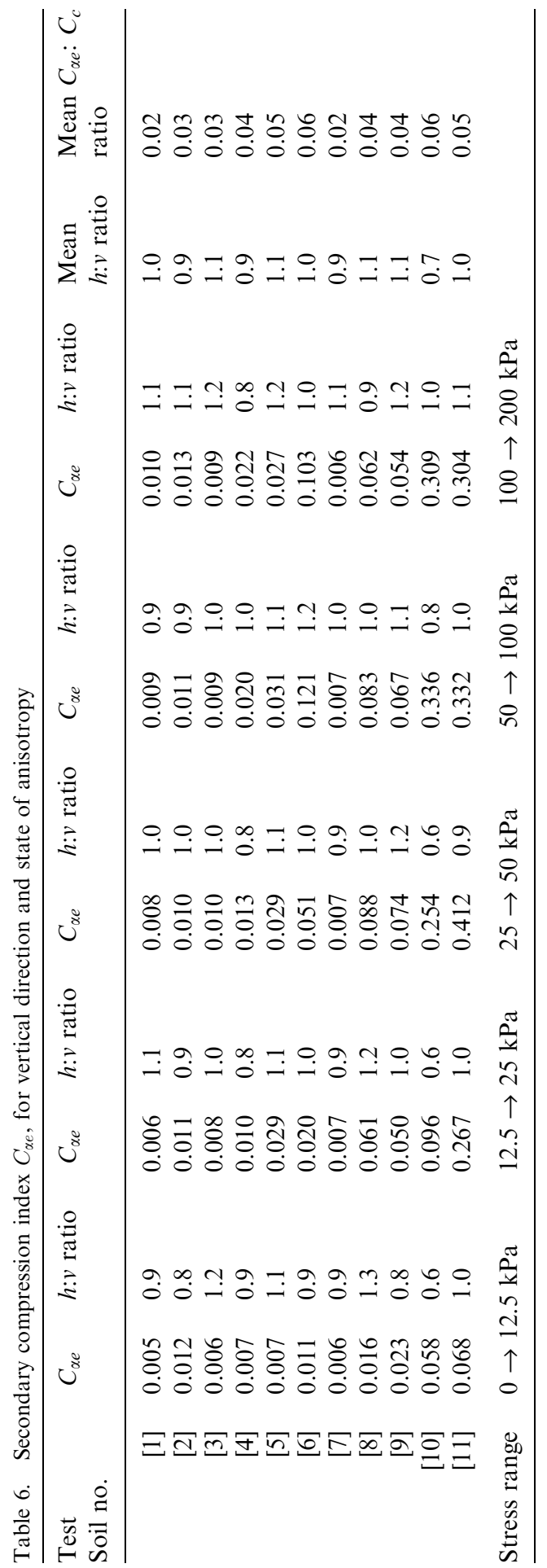



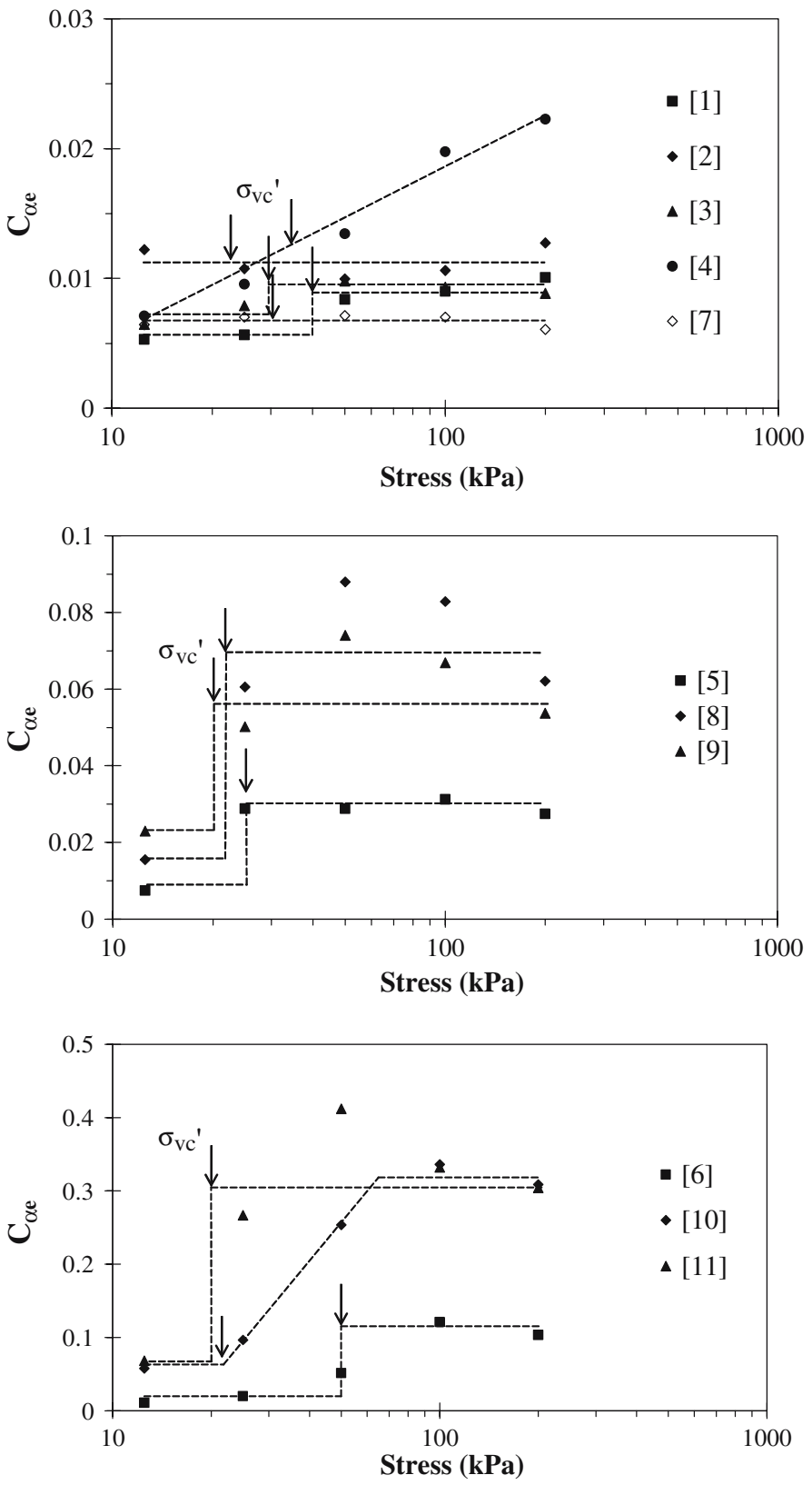

Figure 6. Secondary compression index - log vertical effective stress.

Compression of these features at higher effective stresses caused significant reductions in the permeability although the $r_{k}$ values remained independent of the stress level for practical purposes.

- Preloading of the cores of peaty materials occurred during piston sampling due to the cutting resistance of the fibrous plant material. 


\section{Acknowledgements}

The laboratory tests were carried out by Martin Carney, Assedik Assghair and Darren Gavin and this work is gratefully acknowledged. The author would also like to thank Dr. Eric Farrell for his helpful comments during the preparation of this paper.

\section{References}

Basett, D.J. and Brodie, A.F. (1961) A study of Matabitchual varved clay, Ontario Hydro Research News, 13(4), 1-6.

BS5930 (1999) Code of Practice for Site Investigations, British Standards Institution, London.

Casagrande, A. (1936) The determination of the preconsolidation load and its practical significance, in Proceedings of the First International Conference on Soil Mechanics and Foundation Engineering, p. 60.

Casagrande, A. and Fadum, R.E. (1940) Notes on soil testing for engineering purposes. Harvard University Graduate School of Engineering, Publication 8.

Chu, J., Bo, M.W., Chang, M.F. and Choa, V. (2002) Consolidation and permeability properties of Singapore marine clay, Geotechnical and Geoenvironmental Engineering, 128(9), 724-732.

Cortellazzo, G. and Simonini, P. (2001) Permeability evaluation and its implications for consolidation analysis of an Italian soft clay deposit, Canadian Geotechnical Journal, 38, $1166-1176$.

Das, B.M. (1997) Advanced Soil Mechanics, Taylor and Francis, Washington.

Head, K.H. (1992) Manual of Soil Laboratory Testing: (1) Soil Classification and Compaction Tests, Pentech Press, London.

Lambe, T.W. and Whitman, R.V. (1979) Soil Mechanics, John Wiley and Sons, Singapore.

Leroueil, S., Bouclin, G., Tavenas, F., Bergeron, L. and LaRochelle, P. (1990) Permeabilityanisotropy of natural clays as a function of strain, Canadian Geotechnical Journal, 27, $568-579$.

Leroueil, S., Lerat, P., Hight, D.W. and Powell, J.J.M. (1992) Hydraulic conductivity of a recent estuarine silty clay at Bothkennar, Géotechnique, 42(2), 275-288.

Lumb, P. and Holt, J.K. (1968) The undrained shear strength of a soft marine clay from Hong Kong, Géotechnique, 18, 25-36.

Mesri, G., Shahien, M. and Feng, T.W. (1995) Compressibility parameters during primary consolidation, in Proceedings of the International Symposium on Compression and Consolidation of Clayey Soils, Hiroshima, Vol. 2, pp. 1021-1037.

Seah, T.H. and Koslanant, S. (2003) Anisotropic consolidation behavior of soft Bangkok clay, Geotechnical Testing Journal, 26(3), 266-276.

Subbaraju, B.H. (1973) Field performance of drain wells designed expressly for strength gain in soft marine clays, in Proceedings of the Eight International Conference on Soil Mechanics and Foundation Engineering, Vol. 2.2, pp. 217-220.

Taylor, D.W. (1942) Research on consolidation clays. Department of Civil and Sanitation Engineering, Massachusetts Institute of Technology, Report 82.

Tsien, S.I. (1955) Stability of marsh deposits. Highway Research Board, Bulletin 15, pp. $15-43$. 